\title{
Prostate Cancer Awareness and Screening among Men in Eldoret, Kenya
}

\author{
Oyungu Eren, Njiru Evangeline, Mugalo Edward, Wawire Ann Kabimba, Nyamberi Shem, \\ Bundotich Gladys, Nyongesa Susy
}

\begin{abstract}
Background: Prostate cancer remains one of the leading causes of male mortality despite advances in its treatment and prevention. The low level of awareness is thought to contribute to delayed diagnosis and hinders goal-directed interventions in prostate cancer prevention.

Objectives: To determine the level of awareness and screening for prostate cancer among males in a peri-urban population.
\end{abstract}

Design: Descriptive cross-sectional study and cluster sampling was used to select a sample size of 385 men. Data was collected using an interviewer-administered questionnaire which captured information on demographics, level of awareness and screening for prostate cancer.

Setting: The study took place in Maili Nne, Eldoret Municipality in Uasin- Gishu County.

Subjects: Men aged 40 years and above.

Results: Out of the 385 men $112(29.1 \%)$ were aware of prostate cancer. In response to any cancer they had heard of, 42.14\% had heard of breast cancer while $23.5 \%$ and $10.7 \%$ had heard of cervical and prostate cancer respectively. Given a list of possible symptoms of prostate cancer, $67 \%$ could identify at least one symptom. The majority $(56.43 \%)$ did not know any method of screening for prostate cancer, and among those who knew, the tests identified were a urine test, PSA/Blood Test, digital rectal examination and bone test by $17.4 \%, 12.86 \%$ and $10.71 \%$ and $2.9 \%$ respectively. Ten percent of the men had been screened for prostate cancer in the five years preceding the study. There was no significant association between prostate cancer awareness and screening behavior (OR 1.704, 95\% CI 0.868 - 3.347). Men 40 - 50 years were less likely to have been screened. A belief that prostate cancer is curable; having heard of prostate cancer and knowing that prostate cancer affects men only were significantly associated with the probability of having undergone screening.

Conclusion: Awareness of prostate cancer among men in Maili Nne is low, and screening remains unacceptably low. Public health interventions aimed at reducing prostate cancer mortality should aim at increasing awareness as well as behavior change to embrace screening.

Index Terms - Prostate cancer, Awareness, Screening.

\section{INTRODUCTION}

Prostate cancer is the second most common cancer in men, after skin cancer [1]. In Africa, it affects 1 in 6 men [1], and yet only a few studies have been done to determine the level

Oyungu Eren, School of medicine Moi University.

Njiru Evangeline, School of medicine Moi University.

Mugalo Edward, School of medicine Moi University.

Wawire Ann Kabimba, School of nursing Moi University.

Nyamberi Shem, School of nursing Moi University.

Bundotich Gladys, School of nursing Moi University.

Nyongesa Susy, School of nursing Moi University. of awareness among the male population at risk. Although there are no specific prostate cancer burden statistics from Kenya, it has been estimated that there are 1,007 new cases of prostate cancer and about 850 deaths annually [1].

In a study done in Europe among the general public, 39\% of male respondents mentioned prostate cancer as one of the cancers they had heard of [2]. In the same study, the proportion of respondents who knew Digital Rectal Examination (DRE) and urine testing as diagnostic tests for prostate cancer was $15 \%$ and $14 \%$ respectively. The low level of awareness of prostate cancer was in contrast to the high awareness of breast cancer ([9\%] among women (2).

A study conducted in Nigeria (3) on Level of Awareness, Perception and Screening Behavior Regarding Prostate Cancer, found that $156(39.2 \%)$ respondents had heard of prostate cancer, while $66(16.6 \%)$ were able to identify where the prostate gland is located, an indication that the awareness about the disease was low.

In a New York study among men aged 50 years and older, fewer than $10 \%$ of the men perceived their prostate cancer risk to be high, and almost $20 \%$ perceived no risk of developing the disease [4]. Approximately $60 \%$ of the men reported having had a prostate-specific antigen (PSA) test. Physician advice was significantly associated with screening for prostate cancer and the methods used were a PSA test and digital rectal examination.

Based on racial differences in mortality ascribed to prostate cancer in America, Weinrich et al. concluded that lack of knowledge regarding prostate cancer screening and lack of participation in the screening procedures were the main underlying factors [4]. In their study, they found that only $14 \%$ and $18 \%$ of African Americans had a high level of prostate cancer knowledge and had heard of prostate-specific antigen (PSA) and digital rectal examination (DRE) as diagnostic tests for early detection of prostate cancer respectively [4].

Although prostate cancer is a public health problem all over the world, there is lack of statistics from developing world [1] that would help to advise strategies to improve knowledge, awareness, and practice as well as serve as a baseline for evaluation of such interventions. This study was carried out to bridge this gap in knowledge by determining awareness and specific knowledge among men aged 40 years and above. Also, the study reports on the frequency of prostate cancer screening and whether there is any association between awareness and screening. 


\section{MATERIALS AND METHODS.}

This study was a descriptive cross-sectional study carried out in Maili Nne estate in Uasin Gishu County, Kenya which is a peri-urban community. The study population was all male residents aged 40 years and above. Maili Nne was divided into six clusters based on the six administrative villages. Every third homestead in a cluster was selected, and all the male members who satisfied the study criteria were interviewed until the requisite 385 respondents had been interviewed. Men who had had prostate cancer were excluded. This study was approved by the Institutional Research and Ethics Committee (IREC) of Moi University College of Health Sciences. Informed consent was obtained from each participant. Data was collected using an interviewer-administered questionnaire. The items on the questionnaire were divided into three sections covering demographics, level of awareness and screening behaviour towards prostate cancer. Data collected included age in years, religion, occupation, education level, level of awareness, knowledge of methods of screening and screening frequency.

Awareness in this study was judged as having in-depth knowledge about prostate cancer. Determining the level of prostate cancer awareness was based on responses to nine questions that captured spontaneous responses about the type of cancer heard of, direct question whether respondents had heard of prostate cancer, what gender is affected, risk factors, measures of reducing risk factors, signs and symptoms associated, modes of treatment and prognosis of prostate cancer. Each positive response earned the respondent one point, and each negative or uncertain response earned zero points. The total score was calculated, and respondents who scored $50 \%$ and above were considered to have awareness.

Descriptive statistics were used to calculate frequency and percentage in various categories. Awareness was calculated as a percentage of total respondents who were aware. The association between awareness and screening was analysed using multivariate logistic regression.

\section{RESULTS}

\section{A. Demographic Characteristics}

A total of 385 respondents were interviewed. Fifty percent were in the age group of 40 to 50 years while $22.15,20.7 \%$ and $7.14 \%$ were in the age groups 51 to $60,61-70$ and above 70 years respectively. Eighty-five percent were Christians while Muslims and Hindus were $14.3 \%$ and $0.7 \%$ respectively. Of all the respondents, $40.71 \%$ had attained secondary level education while $30.71 \%, 23.57 \%$, and $5 \%$ had attained tertiary, primary and informal education.

\begin{tabular}{|c|c|c|}
\hline Variable & Frequency & \begin{tabular}{|l|l|} 
Percentage \\
\end{tabular} \\
\hline $\begin{array}{l}\text { Marital Status } \\
\text { Married } \\
\text { Single } \\
\text { Divorced } \\
\text { Separated } \\
\end{array}$ & \begin{tabular}{|l|}
272 \\
69 \\
31 \\
13 \\
\end{tabular} & \begin{tabular}{|l|}
70.6 \\
17.9 \\
8.1 \\
3.4 \\
\end{tabular} \\
\hline 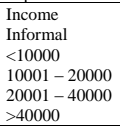 & \begin{tabular}{|l|}
238 \\
64 \\
24 \\
35 \\
24 \\
\end{tabular} & \begin{tabular}{|l|}
61.8 \\
16.6 \\
6.2 \\
9.1 \\
6.2 \\
\end{tabular} \\
\hline $\begin{array}{l}\text { Age group } \\
40-60 \\
51-60 \\
61-70 \\
>70 \\
\end{array}$ & \begin{tabular}{|l}
193 \\
85 \\
80 \\
27 \\
\end{tabular} & \begin{tabular}{|l|}
50.1 \\
22.1 \\
20.8 \\
7 \\
\end{tabular} \\
\hline $\begin{array}{l}\text { Religion } \\
\text { Christian } \\
\text { Muslim } \\
\text { Hindu }\end{array}$ & \begin{tabular}{|l}
327 \\
55 \\
3
\end{tabular} & \begin{tabular}{|l}
84.9 \\
14.3 \\
0.8 \\
\end{tabular} \\
\hline $\begin{array}{l}\text { Education } \\
\text { Primary } \\
\text { Secondary } \\
\text { Tertiary } \\
\text { None } \\
\end{array}$ & \begin{tabular}{|l|} 
\\
81 \\
156 \\
121 \\
19 \\
\end{tabular} & \begin{tabular}{|l|}
23.1 \\
40.5 \\
31.4 \\
4.9 \\
\end{tabular} \\
\hline
\end{tabular}

\section{B. Awareness of prostate cancer}

Out of the 385 respondents, only 112 (29.09\%) were aware of prostate cancer. In response to a direct question whether they had heard of prostate cancer, $58.6 \%$ had heard of it. When asked about the different types of cancer they had heard of $42.14 \%$ mentioned breast cancer, $23.57 \%$ cervical cancer, $14.29 \%$ esophageal cancer and $10.71 \%$ prostate cancer. When given a list of possible symptoms associated with prostate cancer (back pain, hair loss, impotence, difficulty in emptying the bladder, blood in semen and weight loss) $63 \%$ of the respondents were able to mention at least one of the symptoms.

\section{Screening behavior}

Out of all the respondents, $10.4 \%$ had been screened for prostate cancer in the five years preceding the study of whom $5.7 \%$ was by DRE, $3.6 \%$ by PSA and $1.1 \%$ did not know the screening test used. Only $4.29 \%$ had undergone the test within one year, $3.57 \%$ within $2-3$ years and $1.43 \%$ within 4-5 years preceding this study. Regarding knowledge of methods for screening for prostate cancer, the majority $(55.8 \%)$ did not know any method while $17.14 \%, 12.7 \%$, $10.7 \%$ and $2.9 \%$ identified urine test, PSA/Blood Test, Digital Rectal Examination (DRE) and bone test respectively.

There was no significant association between prostate cancer awareness and screening behavior (OR 1.704, 95\% CI 0.868 - 3.347). On multivariate analysis the independent factors that were likely to increase the probability of screening were having heard of prostate cancer, knowing the gender affected by prostate cancer and believe that prostate cancer can be cured. Compared to other age groups, being in the age group of 40 to 50 years significantly decreased the probability of being screened (table 3). Marital status and religion were not significantly associated with screening (OR 0.99 and 1.323 ; CI $0.407-2.27$ and $0.577-2.54$ respectively). 


\begin{tabular}{|c|c|c|}
\hline \begin{tabular}{|l|} 
Variable \\
\end{tabular} & \begin{tabular}{|l} 
Frequency \\
\end{tabular} & \begin{tabular}{|l|} 
Percentage \\
\end{tabular} \\
\hline \begin{tabular}{|l} 
Type heard of \\
Breast \\
Cervical \\
Oesophagus \\
Prostate \\
Others \\
Don't know
\end{tabular} & $\begin{array}{l}161 \\
93 \\
55 \\
42 \\
11 \\
23\end{array}$ & \begin{tabular}{|l|}
41.8 \\
24.2 \\
14.2 \\
10.9 \\
2.9 \\
6
\end{tabular} \\
\hline $\begin{array}{l}\text { Gender affected } \\
\text { Men } \\
\text { Women } \\
\text { Both men and women } \\
\text { Don't know }\end{array}$ & \begin{tabular}{|l}
143 \\
57 \\
97 \\
88
\end{tabular} & $\begin{array}{l}37.1 \\
14.8 \\
25.2 \\
22.9\end{array}$ \\
\hline $\begin{array}{l}\text { Symptoms of prostate cancer } \\
\text { Blood in urine } \\
\text { Excessive urination } \\
\text { High temperature } \\
\text { A headache } \\
\text { Don't know }\end{array}$ & \begin{tabular}{|l|}
79 \\
66 \\
53 \\
43 \\
144
\end{tabular} & \begin{tabular}{|l|}
20.5 \\
17.1 \\
13.8 \\
11.2 \\
37.4
\end{tabular} \\
\hline $\begin{array}{l}\text { Risk Factors } \\
\text { Venereal Diseases Exercise } \\
\text { Drinking alcohol } \\
\text { Family history } \\
\text { Old age } \\
\text { Exercise } \\
\text { Stress } \\
\text { Don't know }\end{array}$ & $\begin{array}{l}56 \\
52 \\
51 \\
43 \\
35 \\
26 \\
122\end{array}$ & $\begin{array}{l}14.5 \\
13.5 \\
13.2 \\
11.2 \\
9.1 \\
6.8 \\
31.7\end{array}$ \\
\hline $\begin{array}{l}\text { Treatment } \\
\text { Surgery } \\
\text { Chemotherapy } \\
\text { Hormone therapy } \\
\text { Radiotherapy } \\
\text { Don't know }\end{array}$ & \begin{tabular}{|l|}
80 \\
59 \\
38 \\
33 \\
118
\end{tabular} & \begin{tabular}{|l|}
20.8 \\
15.3 \\
9.9 \\
8.6 \\
30.6
\end{tabular} \\
\hline $\begin{array}{l}\text { Ways of diagnosis } \\
\text { Urine test } \\
\text { Blood test/PSA } \\
\text { Direct Rectal Examination } \\
\text { Bone test } \\
\text { Don't Know }\end{array}$ & \begin{tabular}{|l|}
69 \\
49 \\
41 \\
11 \\
215
\end{tabular} & $\begin{array}{l}17.9 \\
12.7 \\
10.6 \\
2.9 \\
55.8\end{array}$ \\
\hline
\end{tabular}

\begin{tabular}{|c|c|c|c|c|}
\hline \multirow[t]{2}{*}{$\begin{array}{l}\text { Variable } \\
\end{array}$} & \multirow[t]{2}{*}{ ODDS RATIO } & \multirow[t]{2}{*}{ Significance } & \multicolumn{2}{|c|}{$95 \%$ confidence interval } \\
\hline & & & $\begin{array}{l}\text { Lower } \\
\text { bound }\end{array}$ & $\begin{array}{l}\text { Upper } \\
\text { bound }\end{array}$ \\
\hline $\begin{array}{l}\text { Age group } \\
40 \text { to } 50 \text { years } \\
\text { Over } 50 \text { years } \\
\end{array}$ & $\begin{array}{l}.4 \\
\text { Ref }\end{array}$ & $.04 *$ & .164 & .96 \\
\hline $\begin{array}{l}\text { Education } \\
\text { Primary } \\
\text { Any other level or none }\end{array}$ & $\begin{array}{l}.47 \\
\text { Ref }\end{array}$ & .26 & .13 & 1.7 \\
\hline $\begin{array}{l}\text { Type of cancer known } \\
\text { Prostate cancer } \\
\text { Any other cancer or none }\end{array}$ & $\begin{array}{l}6.7 \\
\text { Ref }\end{array}$ & $.000^{*}$ & 2.4 & 18.9 \\
\hline $\begin{array}{l}\text { Prostate cancer symptoms } \\
\text { Knew } \\
\text { Did not know }\end{array}$ & $\begin{array}{l}1.1 \\
\text { Ref }\end{array}$ & .82 & .45 & 2.8 \\
\hline $\begin{array}{l}\text { Gender affected by } \\
\text { prostate cancer } \\
\text { Knew } \\
\text { Did not Know }\end{array}$ & $\begin{array}{l}.14 \\
\text { Ref }\end{array}$ & $.000^{*}$ & .05 & .38 \\
\hline $\begin{array}{l}\text { Risk factors for cancer } \\
\text { Knew } \\
\text { Did not know }\end{array}$ & $\begin{array}{l}1.141 \\
\text { Ref }\end{array}$ & .78 & .45 & 2.8 \\
\hline $\begin{array}{l}\text { Thought there is a cure } \\
\text { for prostate cancer } \\
\text { Yes } \\
\text { No }\end{array}$ & $\begin{array}{l}8.75 \\
\text { Ref } \\
\end{array}$ & $.001^{*}$ & 3.2 & 24 \\
\hline
\end{tabular}

\section{DISCUSSION}

This study has demonstrated a low level of prostate cancer awareness, with only $29 \%$ of respondents being aware. Other studies have reported similarly low levels of awareness and knowledge of prostate cancer. Arafa et al. in their study in Egypt, Saudi Arabia, and Jordan, reported low knowledge scores in all the three countries [5]. Olodimejio et al. in Nigeria reported knowledge score of 5.8 out of a maximum of 16 points [6].

Similarly, Ajabe in Nigeria found that only $21.2 \%$ of men surveyed had information on prostate cancer [7]. Knowledge gaps and low awareness of prostate cancer have been reported in developed countries too. A survey in Europe and the USA reported that only $39 \%$ of men were aware of prostate cancer [1].

When we compare the percentage of men aware of prostate cancer on direct questioning (58.6\%) and those aware based on knowledge score $(29 \%)$, there is a significant disparity. In
Nigeria, Olodimejio reported awareness based on one direct question as $80 \%$ but on assessing knowledge the score was less than $30 \%$ [6]. The results suggest that even though men may have heard of prostate cancer, it does not directly lead to knowledge about prostate cancer and therefore may not influence health-seeking behavior.

Four times more men knew of breast cancer as compared to those who knew about prostate cancer, yet breast cancer mainly affects women. The reason may be more public health awareness campaigns for breast cancer, and this could be used to inform public health interventions in prostate cancer. Only $37.1 \%$ of men knew that prostate cancer affects men only which is a gap in prostate cancer knowledge. Similarly, an independent poll by Prostate Cancer Charity in 2008 found only 1 in 10 men knew where the prostate gland is located [8], while Arnold-Reed found that $80 \%$ of men did not know the functions of the prostate [9]. Two-thirds of the respondents knew at least one symptom of prostate cancer. Majority, however, identified blood in urine as a symptom, yet this is a late symptom and therefore suggests that men identify prostate cancer in a late-stage which may not be amenable to curative treatment.

In this study, only $24.4 \%$ knew the risks of prostate cancer. The rest of the responses demonstrated poor understanding and misconceptions regarding risks of prostate cancer. In Uganda, a study on knowledge of prostate cancer among men reported that only a third of men were able to identify risk factors for prostate cancer [10]. Similar studies have been reported in the USA [11]. Knowledge about investigations used to diagnose prostate cancer was equally limited whereby over half of the respondents were not aware of any investigation. Inadequate knowledge of risk factors and diagnosis of prostate cancer may impact negatively on efforts aimed at increasing early screening for prostate cancer.

The low rate of awareness parallels the low rate of screening, with only $10.4 \%$ of the men having been screened for prostate cancer. In one study in Nigeria, no man had been screened for prostate cancer through $21.2 \%$ were aware of prostate cancer [7]. In Oyo state in Nigeria, a screening rate of $4.5 \%$ was reported. Awareness of prostate cancer in this latter study was based on one direct question and reported as $80 \%$, however, when a knowledge score based on causation, treatment, and prevention was computed the mean score was about 30\%, and therefore both screening and knowledge score was low [6]. In the Arabian communities, screening was reported at $8-30 \%$ similar to the finding in this study [5]. The rate of screening in developing countries seems to fall below $30 \%$ which is much lower than the reported rates of above $60 \%$ in the European nations [12]. This difference could be explained by among other factors, lack of vigorous public health campaigns in the developing countries.

Awareness of prostate cancer in our study was not a significant predictor of being screened. Lambert et al. reported similar findings where $75 \%$ of men knew about prostate cancer, but only $26 \%$ had been screened for the same [3]. Livingstone in his study compared male doctors and community men, and even though $83 \%$ of the doctors were aware of prostate cancer, only $45 \%$ of them had undergone screening as opposed to the awareness of $55 \%$ but screening 
rate of 56\% among community men [14]. There might be other predictors of prostate cancer screening in addition to or independent of awareness.

It has been reported that men over 50 years are at higher risk of prostate cancer, however in high-risk populations like black Americans and those with a family history of cancer the risk is higher at a younger age. The risk in our population is, however, unknown, and most people are unaware of the family history of the disease. Therefore, men do not seek screening early. In this study, it was found that men in the age group of 40-50 years were less likely to have undergone screening which may be explained by the low level of awareness.

Men who mentioned prostate cancer as one of the cancers they knew and those who knew that cancer affects men only were more likely to be screened. It has been shown that increased knowledge directly leads to increased uptake of screening [19], [20], [21]. Our study supports the need for increased education on prostate cancer understanding in order to increase screening.

Men who believed that prostate cancer had a cure were more likely to go for screening. The preceding is in line with the health belief theory [22] which would lead to an individual's perceived benefits from health intervention to outweigh barriers. Education, religion and marital status were not significantly associated with the probability of screening which is similar to findings in China and Italy [23]. However, in Nigeria one study reported that education was correlated with screening for prostate cancer [25]. The findings suggest that the influence of level of education on the probability of screening is controversial and may be dependent on other contextual factors.

\section{CONCLUSION}

Awareness of prostate cancer among men in Maili Nne is low, and screening remains unacceptably low. Public health interventions aimed at reducing prostate cancer mortality should aim at increasing awareness as well as embrace screening.

\section{REFERENCES}

[1] J. Ferlay, H. R. Shin, F. Bray, D. Forman, C. D. Mathers and D. Parkin Estimates of worldwide burden of cancer in 2008 (GLOBOCAN 2008). Int J Cancer.

[2] 2010;127(12):2893-917. Available https://www.ncbi.nlm.nih.gov/pubmed/21351269: 07/05/15]

[3] J. M. Fitzpatrick, R. S. Kirby, C. L. Brough, and A. L. Saggerson. Awareness of prostate cancer among patients and the general public: results of an international survey. Prostate Cancer Prostatic Dis. 2009; 12(4): $\quad$ pp. 347-54. Available at: https://www.ncbi.nlm.nih.gov/pmc/articles/PMC2834358/ [Accessed 1 April 2015.]

[4] N. O. Atulumah, M. F. Olanrewaju, A. M. Amosu, and O. Adedeji. Level of Awareness, Perception and Screening Behavior Regarding Prostate Cancer Among Men in a Rural Community of Ikenne Local Government Area, Nigeria. Primary Prevention Insights 2010;2:11 20. Available

http://insights.sagepub.com/level-of-awareness-perception-and-screen ing-behavior-regarding-prostat-article-a2285 [Accessed: 3/9/15]

[5] S. P. Weinrich, M. C. Weinrich, M. D. Boyd and C. Atkinson. The impact of prostate cancer knowledge on cancer screening. Oncology Nursing Forum 1998; 25(3):527-534

[6] M. A. Arafa, D. M. Rabah, and I. H. Wahdan. Awareness of the general public towards cancer prostate and screening practice in Arabic communities: a comparative multi-center study. Asian Pac J Cancer Prev. 2012; 13(9): 4321-6.

[7] O. Olodimeji, Y. O. Bidemi, J.A. Olufisayo, A. O. Sola. Prostate cancer awareness, knowledge, and screening practices among older men in Oyo state, Nigeria. Int Community Health Educ. 2010;30(3):271 - 86.

[8] A. A. Ajape, A. Babata, O. O. Abiola. Knowledge of prostate cancer screening among native African urban population in Nigeria. Nig QJ Hosp Med. 2010; 20(2):94-6

[9] G. Diebel. Prostate cancer awareness. British Journal of Healthcare Assistants. 2011;5(3): 148 -149.

[10] D. E. Arnold-Reed, D. A. Hince, M. K. Bulsara, H. Ngo, M. Eaton, A. R. Wright, F. R. Jones, W. Kaczmarczyk, A. G. Marangou, T. D. Brett. Knowledge and attitudes of men about prostate cancer. Med J Aust. 2008;189 (6): 312-314

[11]

[12] H. Nakandi, M. Kirabo, C. Semugabo, A. Kittengo, P. Kitayimbwa, S. Kalungi, J. Maena. Knowledge, attitudes and practices of Ugandan men regarding Prostate Cancer. African Journal of Urology. 2013; 19(4): $165-170$.

[13] C. B. Steele, D. S. Miller, C. Maylahn, R. J. Uhler and C. T. Baker. Knowledge, attitudes, and screening practices among older men regarding prostate cancer. American Journal of Public Health: 2000;90 (10):1595-1600. Available at: http://ajph.aphapublications.org. [Accessed 30 Jan 2015.]

[14] A. Fearing, D. Bell, M. Newton, S. Lambert. Prostate screening health beliefs and practices of African American men. Abnf J. 2000;11(6):141-4.

[15] S. Lambert, A. Fearing, D. Bell, M. Newton. A comparative study of prostate screening health beliefs and practices between African American and Caucasian men. BNF J. 2002; 13(3):61-3.

[16] P. Livingston, P. Cohen, M. Frydenberg, R. Borland, D. Reading, V Clarke, D. Hill. Knowledge, attitudes and experience associated with testing for prostate cancer: a comparison between male doctors and men in the community. Intern Med 2002;32(5-6):215-23.

[17] K. J. Pienta. Critical appraisal of prostate Specific antigen in prostate cancer screening: 20 years later. Urology. 2009: 73(5 suppl): S11-20.

[18] C. S. Rodgers. Perspectives on Prostate Cancer Screening. Int J Clin Pract. 2011;65:31-34.

[19] M. J. Duffy. Prostate Specific antigen does the current evidence support its use in cancer screening? Ann. Clin. Biochem. 2011; 48:310-316. DOI: $10.1258 /$ acb.2011.010273

[20] D. Illic, D. O'Connor, S. Green, T. J. Wilt. Screening for prostate cancer: an updated Cochrane Systemic Review. BJUI International. 2011;107(6); $882-891$

[21] S. P. Weirch, M. C. Weinrich, M. D. Boyd, C. Atkinson. The impact of prostate cancer knowledge on cancer screening. Oncol Nurs Forum. 1998; 25(3):527 -34

[22] L. Ross, T. Dark, H. Orom, D. Underwood, C. Anderson -Lewis, J. Johnson, D. O. Erwin Patterns of information behavior and prostate cancer knowledge among African American men. J. Cancer Educ. 2011; 26(4):708-16

[23] J. Pendleton, C. Hopkins, S. Anai, K. Nakamura, M. Chang, A. Grissett. Prostate cancer knowledge and screening attitudes of inner-city men. Journal of Cancer Education. 2008;23(3): pp. 172-179. Available at: https://www.ncbi.nlm.nih.gov/pubmed/18709589 [accessed: 30/01/2013]

[24] K. J. Nancy, H. B. Marshall. The Health Belief Model: A Decade Later Health Education Behavior. 1984;11 (1):1-47

[25] W. K. W. So, K. C. Cho, W. P. Y. Tang, P. C. Lee, A. T. Y. Shin, S. S M. Ho, H. Y. L. Chan, W. W.T. Lam, W. B. Goggins, C. W. H. Chan. Uptake of prostate cancer screening and associated factors among Chinese men aged 50 or more: a population-based survey. Cancer Biol Med. 2014;11(1):56-63

[26] M. Morlando, C. P. Pelullo, G. Di Giuseppe. Prostate cancer screening: Knowledge, attitudes and practices in a sample of men in Italy. A survey. PLoS One. 2017;12(10):e0186332. Available at http://journals.plos.org/plosone/article?id=10.1371/journal.pone. 0186 332. [Accessed 12/08/2018]

[27] R. W. Ojewola, E. S. Oridota, O. S. Balogun, E. O. Ogundare, T. O. Alabi, O. O. Banjo, A. Laoye, B. Adetunmbi, B. O. Adebayo, R Oluyombo. Knowledge, attitudes and screening practices regarding prostatic diseases among men older than 40 years: a population-based study in Southwest Nigeria. Pan Afr Med J 2017; 27: 151. Available at https://www.ncbi.nlm.nih.gov/pmc/articles/PMC5567951/ [Accessed: $12 / 08 / 2018]$ 